\title{
Singapore multidisciplinary consensus recommendations on muscle health in older adults: assessment and multimodal targeted intervention across the continuum of care
}

Samuel T. H. Chew ${ }^{1,2^{*}}$ (D), Geetha Kayambu ${ }^{3}$, Charles Chin Han Lew ${ }^{4}$, Tze Pin $\mathrm{Ng}^{5}$, Fangyi Ong ${ }^{4}$, Jonathan $\operatorname{Tan}^{6}$, Ngiap Chuan $\operatorname{Tan}^{7}$ and Shuen-Loong Tham ${ }^{8,9}$

\begin{abstract}
Background: The rapidly aging societies worldwide and in Singapore present a unique challenge, requiring an integrated multidisciplinary approach to address high-value targets such as muscle health. We propose pragmatic evidence-based multidisciplinary consensus recommendations for the assessment and multi-modal management of muscle health in older adults ( $\geq 65$ years) across the continuum of care.

Methods: The recommendations are derived from an in-depth review of published literature by a multidisciplinary working group with clinical experience in the care of the older population in both acute and community settings.

Results: The panel recommends screening for muscle impairment using the SARC-F questionnaire, followed by assessment for low muscle strength (handgrip strength or 5-times chair stand test $\geq 10 \mathrm{~s}$ as a surrogate for lower limb strength) to diagnose possible/probable sarcopenia. For uncomplicated cases, lifestyle modifications in exercise and diet can be initiated in the community setting without further assessment. Where indicated, individuals diagnosed with possible/probable sarcopenia should undergo further assessment.

Diagnosis of sarcopenia should be based on low muscle strength and low muscle mass (bioimpedance analysis, dualenergy X-ray absorptiometry or calf circumference as a surrogate). The severity of sarcopenia should be determined by assessment of physical performance (gait speed or 5 -times chair stand test $\geq 12 \mathrm{~s}$ as a surrogate for gait speed). To treat sarcopenia, we recommend a combination of progressive resistance-based exercise training and optimization of nutritional intake (energy, protein and functional ingredients). High quality protein in sufficient quantity, to overcome anabolic resistance in older adults, and distributed throughout the day to enable maximum muscle protein synthesis, is essential. The addition of resistance-based exercise training is synergistic in improving the sensitivity of muscle protein synthesis response to the provision of amino acids and reducing anabolic resistance. An expected dose-response (Continued on next page)
\end{abstract}

\footnotetext{
*Correspondence: samuel.chew.t.h@singhealth.com.sg

'Department of Geriatric Medicine, Changi General Hospital, 2 Simei Street 3,

Singapore 529889, Singapore

${ }^{2}$ Society for Geriatric Medicine Singapore, Singapore, Singapore

Full list of author information is available at the end of the article
}

(c) The Author(s). 2021 Open Access This article is licensed under a Creative Commons Attribution 4.0 International License, which permits use, sharing, adaptation, distribution and reproduction in any medium or format, as long as you give appropriate credit to the original author(s) and the source, provide a link to the Creative Commons licence, and indicate if changes were made. The images or other third party material in this article are included in the article's Creative Commons licence, unless indicated otherwise in a credit line to the material. If material is not included in the article's Creative Commons licence and your intended use is not permitted by statutory regulation or exceeds the permitted use, you will need to obtain permission directly from the copyright holder. To view a copy of this licence, visit http://creativecommons.org/licenses/by/4.0/ The Creative Commons Public Domain Dedication waiver (http://creativecommons.org/publicdomain/zero/1.0/) applies to the data made available in this article, unless otherwise stated in a credit line to the data. 
(Continued from previous page)

relationship between the intensity of resistance-based training, lean mass and muscle strength is described.

Conclusions: Reviewed and endorsed by the Society of Rehabilitation Medicine Singapore and the Singapore Nutrition and Dietetics Association, these multidisciplinary consensus recommendations can provide guidance in the formulation of comprehensive and pragmatic management plans to improve muscle health in older adults in Singapore and Asia.

Keywords: Muscle, Sarcopenia, Older adult, Multidisciplinary, Exercise, Nutrition, Consensus

\section{Background}

Aging is accompanied by a loss of muscle health which includes progressive loss of muscle mass and function [1-3]. Loss of muscle mass and function are associated with negative outcomes such as clinical complications, lower physical function, poor quality-of-life, longer length of hospitalization, morbidity and mortality, and higher healthcare costs [4-7]. For the purpose of this paper, muscle health is defined as having adequate muscle mass and muscle function.

Decline in function (defined as muscle strength and/or physical performance) and muscle mass are the defining features of sarcopenia [8-10]. These are predominantly associated with aging (primary sarcopenia), while systemic disease, physical inactivity or malnutrition are implicated in secondary sarcopenia $[9,10]$. Sarcopenia is estimated to affect approximately $10 \%$ of communitydwelling older adults globally [11] and is prevalent in up to $33 \%$ of frail older adults in nursing homes [12] and $22-26 \%$ of older adults in inpatient settings [13].

In Singapore, $44 \%$ of adults $\geq 65$ years old attending specialist outpatient clinics were at risk of sarcopenia based on the SARC-F questionnaire [14]. Sarcopenia, diagnosed using the Asian Working Group for Sarcopenia (AWGS) 2014 criteria, was reported in $25 \%$ of community-dwelling and functionally independent older adults aged $\geq 50$ years [15] and $27.4 \%$ of older adults (60-78 years old) with type 2 diabetes in a primary care setting [16]. In a cross-sectional study of 811 community-dwelling independently ambulant older adults > 65 years old at risk of malnutrition (defined by Malnutrition Universal Screening Tool score $\geq 1$ ) in Singapore, the prevalence of sarcopenia based on the AWGS 2014 criteria increased significantly to $70 \%$ [17]. In addition, these subjects with sarcopenia were found to have lower total energy intake and energy-adjusted protein intake based on 24-h dietary recall [17]. This study also reported a prevalence of $81.3 \%$ for low appendicular skeletal mass index (ASMI) based on the AWGS 2014 cut-offs [17], a striking four-fold increase compared with a nourished cohort with similar baseline characteristics where the prevalence for low ASMI was only 20.6\% [18]. These findings are concerning as one in two Singaporeans aged $>65$ years is expected to become severely disabled and require long-term care in their lifetime [19].

The importance of muscle health remains under-recognized across healthcare settings [20-22]. An international survey found that only $50 \%$ of clinicians measured at least one muscle parameter in patients aged $\geq 60$ years [23]. Majority of healthcare professionals (HCPs) lack guidance on the recognition, assessment and management of muscle health [20, 24]. Other barriers include time constraints; complexity of measurement variables; a paucity of population-specific cut-offs for these measures; and lack of collaboration [9, 22, 24].

Several international and regional guidelines and consensus recommendations on sarcopenia and muscle health are available $[9,10,25]$, including the recently revised AWGS 2019 Consensus Update on Sarcopenia Diagnosis and Treatment (AWGS 2019), which also provided cut-off values for the screening and diagnosis of sarcopenia based on Asian patients [26]. While some of these guidelines provide recommendations to prevent and improve sarcopenia $[10,25,26]$, they may be too broad or too specific in nature for use in the clinical setting directly. We aim to bridge this gap through a multidisciplinary review using a Delphi-like approach to meet the needs for concise and pragmatic consensus recommendations for optimizing muscle health in older adults aged $\geq 65$ years in Singapore. We aim to complement the recommendations from AWGS 2019 by proposing an additional surrogate measure for lower limb strength, as well as providing a more detailed and targeted approach in terms of interventions to improve nutrition and muscle health in older patients. We also aim to provide more input from a multidisciplinary and holistic point of view, and to propose some population-based strategies which will complement the strength of the multiple stakeholders involved in the care of this sub-group of older people in Singapore who may be at risk of poor muscle health. These recommendations are intended for HCPs in the clinical settings across the continuum of care in the community, outpatient, inpatient and longterm care settings.

\section{Methods}

These recommendations were developed by a multidisciplinary working group of eight senior clinicians and researchers in geriatrics, dietetics, gerontology, intensive care medicine, family medicine, physiotherapy and rehabilitation medicine to encompass the entire continuum of care. 
STH Chew is a Senior Consultant Geriatrician and the Principal Investigator for the SHIELD study $[17,18]$ in community dwelling older adults in Singapore, G Kayambu $(\mathrm{PhD})$ is a Senior Physiotherapist and Director for Departmental Research, National University Hospital Singapore, C Lew $(\mathrm{PhD})$ is a Principal Dietitian and Researcher in Nutrition, TP Ng is a Medical Epidemiologist in Academia, Researcher and the Principle Investigator for the Singapore Longitudinal Ageing Study (SLAS, ClinicalTrials.gov Identifier: NCT03405675), F Ong is a Principal Dietitian with extensive clinical experience supporting nutrition in older patients across the continuum of care, J Tan is a Senior Consultant Anaesthetist, a founding member of and the current Scientific Chair for the Singapore Society for Parenteral and Enteral Nutrition (SingSPEN), NC Tan is a Senior Consultant Family Physician, clinician-innovator cum the Director of Research for Singhealth Polyclinics with funded studies on sarcopenia in the geriatric population, and SL Tham is a Consultant and Program Director for Rehabilitation Medicine at Tan Tock Seng Hospital.

STH Chew, G Kayambu, C Lew and F Ong, and SL Tham were nominated to represent the Society of Geriatric Medicine Singapore, Singapore of Physiotherapy Association, Singapore Nutrition and Dietetics Association, and Singapore Rehabilitation Association respectively.

The panel convened at a face-to-face meeting in Singapore in late-April 2019 to review and discuss available evidence, share clinical practice experience on the management of muscle health and forge a way forward on how best to apply the current evidence and guidelines in clinical settings. We defined the clinical problem as the following: "In light of the rapidly ageing population in Singapore and Asia, what are the best evidencebased interventions available to optimise muscle health in older adults $>65$ years old that can be delivered by a multidisciplinary team across the continuum of care?"

Prior to the meeting, a targeted literature search using PubMed was conducted with the following keywords and their combinations: sarcopenia, muscle health, elderly, nutrition, protein, vitamin, oral nutritional supplements $(\mathrm{ONS}), \beta$ hydroxy $\beta$-methylbutyrate (HMB), exercise, guidelines, consensus, Asia and Singapore. Draft recommendations were subsequently developed based on major international guidelines on sarcopenia and nutrition $[8,9,12,20,25,27]$, as well as relevant evidence identified from the literature. Our concise and harmonized operational definition and diagnostic criteria for sarcopenia, using SARC-F, muscle strength, muscle mass and physical performance in a step-wise manner, are derived from definitions and criteria proposed by the recently published second European Working Group on Sarcopenia in Older People (EWGSOP2) and AWGS 2019 [9, 26]. The treatment recommendations by AWGS 2019 are themselves guided by the systematic review by Arai et al.
[10]. Where available, we have adopted the cut-off values recommended by the AWGS 2019 [26]. Otherwise, cut-off values from international literature are used.

Following an in-depth discussion at the initial meeting, multiple rounds of e-mail correspondence until 100\% agreement was achieved for each section in an iterative manner took place over the next 6 months. We have also included the updated recommendations from the AWGS 2019 as well as other recent relevant publications. The finalized consensus recommendations with approval from all authors on screening and diagnosis of sarcopenia; physical activity; nutritional interventions (protein, vitamin D, HMB, ONS); and education (patient and $\mathrm{HCP}$ ) are presented in this paper.

These recommendations have been reviewed and endorsed by the Society of Rehabilitation Medicine Singapore and the Singapore Nutrition and Dietetics Association. The Singapore Physiotherapy Association has also reviewed and provided invaluable input on the recommendations, particularly in the sections on interventions for muscle health, the structured resistance exercise training (RET)-based exercise program, and population-based strategies for muscle health.

\section{Results}

Tables 1 and 2 lists the recommendations developed based on international and regional evidence, and clinical perspectives contextualized to Singapore.

\section{Importance of muscle health \\ Recommendation 1}

The importance of muscle health (mass, strength, and function) should be emphasized across the continuum of care.

Impaired muscle health contributes to adverse clinical and functional outcomes in inpatient, outpatient and long-term care settings $[6,28]$. Impairments in muscle mass and function increase the risk of comorbidities [14, 29, 30]; functional decline and physical disability [31, 32]; risk of falls [14, 33, 34]; and loss of independence in activities of daily living [35].

Sarcopenia and measures of muscle function have been shown to predict the risk of mortality in older individuals in the community, inpatient settings and nursing homes [36-40]. Sub-optimal muscle health is associated with a greater risk of institutionalization, rate and length of hospitalization and re-admissions, and polypharmacy $[14,40-43]$, with a consequent increase in healthcare utilization and expenditure [44-46].

\section{Screening muscle health across the continuum of care Recommendation 2}

Muscle health should be prioritized in older adults ( $\geq 65$ years), particularly in individuals with conditions who may be at risk of sarcopenia. 
Table 1 Summary of sconsensus recommendations on screening and diagnosis for muscle health

Management of muscle health across the continuum of care in Singapore - screening and diagnosis for muscle health

1. The importance of muscle health (mass, strength, and function) should be emphasized across the continuum of care.

2. Muscle health should be prioritized in older adults ( $\geq 65$ years), particularly in individuals with conditions who may be at risk of sarcopenia.

3. In most settings, screening for possible/probable sarcopenia or muscle impairment can be performed using the SARC-F questionnaire, followed by the assessment for low muscle strength via handgrip strength or the 5-times chair stand test with a cut-off of $\geq 10 \mathrm{~s}$ as surrogate measures of muscle strength.

4. Diagnosis of confirmed sarcopenia should be based on the presence of low muscle strength and low muscle mass; for severe sarcopenia, low physical performance is also present in addition to low muscle strength and low muscle mass.

5. In community and outpatient settings, bioimpedance analysis can be used to determine low muscle mass. In the absence of other

alternatives, calf circumference can be used as a surrogate measure of muscle mass in patients without edema and not suspected to have sarcopenic obesity. In inpatient settings, dual-energy X-ray absorptiometry can be used as the reference standard for measuring muscle mass.

6. Physical performance can be measured using the usual gait speed or by using the 5-times chair stand test with a cut-off of $\geq 12 \mathrm{~s}$ as a surrogate measure of gait speed of $1.0 \mathrm{~m} / \mathrm{s}$.

Table 2 Summary of consensus recommendations on interventions for maintaining muscle health

Management of muscle health across the continuum of care in Singapore - recommended interventions for muscle health

7. Progressive resistance/weight-based training is effective for improving muscle mass, strength and physical performance

8. Adequate calorie and protein diet support muscle health for healthy community-dwelling older adults.

9. Supplementation of protein and calories, either via whole foods and/ or high protein oral nutrition supplements, should be the primary focus of any nutrition interventions aimed at optimizing muscle health and recovery in hospitalized patients.

10. Meeting the recommended daily intake of vitamin D (600-800 IU) may improve muscle strength across the continuum of care and vitamin $D$ deficiency should be treated.

11. A combination of physical activity and nutritional interventions is strongly recommended for optimal muscle health in patients with malnutrition and at risk of malnutrition.

12. A multidisciplinary team (physicians, dietitians/nutritionists, physiotherapists, nurses and other relevant healthcare professionals) is essential for optimizing muscle health in all settings.

13. Patients and caregivers should be educated on the importance of combining physical activity and nutritional interventions for improving muscle health.

14. Across all healthcare settings, urgent initiatives are required to raise awareness, educate and skill relevant healthcare professionals on screening, prevention and management of poor muscle health.
From the age of 40 , about $8 \%$ of lean body mass (LBM) loss per decade is expected. This increases to about $15 \%$ per decade after age 70 ; by the age of 80 , there is an expected loss of up to $39 \%$ of LBM from peak LBM [47-49]. We therefore propose prioritizing muscle health before the onset of peak muscle loss. Muscle health should be re-evaluated after major acute illness or prolonged hospitalization, as the increased inflammatory burden and bed rest during these states may precipitate the loss of muscle mass, strength and functional capacity in older adults $[13,50]$.

We support the findings of the taskforce for the International Clinical Practice Guidelines for Sarcopenia, which recommends annual screening and additional screening after major health events in individuals $>65$ years of age [25]. Further case finding and prioritization of screening can be undertaken in patients with conditions associated with sarcopenia such as old age, frailty, malnutrition, chronic illnesses, cognitive impairment and recurrent falls [26].

\section{Recommendation 3}

In most settings, screening for possible/probable sarcopenia or muscle impairment can be performed using the SARC-F questionnaire, followed by the assessment for low muscle strength via handgrip strength or the 5-times chair stand test with a cut-off of $\geq 10 \mathrm{~s}$ as surrogate measures of muscle strength.

Across all healthcare settings, screening for muscle health and sarcopenia should be rapid and convenient. In line with recent guidelines, we suggest using the SARC-F questionnaire for screening, followed by the assessment for low muscle strength via handgrip strength or the 5-times chair stand test (5CST) as a surrogate measure of lower limb strength [9, 51, 52]. Recommended cut-off values are presented in Table 3. The 5item SARC-F questionnaire has been shown to be useful in Asian older adults [55-58], with a score of $\geq 4$ predictive of adverse functional outcomes [53]. The SARC-F demonstrates high specificity, but has low sensitivity [58, 59]. Handgrip strength correlates well with lower limb strength and is widely used as a measure of overall strength in studies on sarcopenia and frailty [60]. Specific measurement techniques are required for accurate measurements. The recommended cut-off values for Asian population are $<28 \mathrm{~kg}$ for males and $<18 \mathrm{~kg}$ for females [26].

In the AWGS 2019 guidelines, handgrip strength is the sole measure of strength [26]. However, the chair stand test (CST) can also be used as a proxy for lower leg strength [9]. The EWGSOP2 recommends the 5CST test, which measures the time to stand up from a standard chair five times, as a surrogate measure of muscle strength in the lower limbs [9]. The 5CST fulfils an 
Table 3 Recommended tools for assessment of muscle health with cut-off values for the Singapore population

\begin{tabular}{|c|c|c|c|}
\hline Parameter & Recommended tool & $\begin{array}{l}\text { Recommended cut-off value for low muscle } \\
\text { parameters }\end{array}$ & Reference \\
\hline $\begin{array}{l}\text { Physical activity related to } \\
\text { muscle }\end{array}$ & SARC-F questionnaire & $\begin{array}{l}\text { Score of } \geq 4 \text { out of } 10 \text {, indicative } \\
\text { of sarcopenia }\end{array}$ & $\begin{array}{l}\text { Malmstrom et al., } 2016 \text { [53]; AWGS } \\
2019 \text { [26] }\end{array}$ \\
\hline \multirow[t]{2}{*}{ Muscle strength } & Handgrip strength & $\begin{array}{l}\text { Men: }<28 \mathrm{~kg} \\
\text { Women: }<18 \mathrm{~kg}\end{array}$ & AWGS 2019 [26] \\
\hline & $\begin{array}{l}\text { 5-times CST test (surrogate } \\
\text { measure) }\end{array}$ & $\geq 10$ s for 5 rises & Makizako et al., 2017 [54] \\
\hline \multirow[t]{3}{*}{ Muscle mass } & BIA (ASMI) & $\begin{array}{l}\text { Men: }<7.0 \mathrm{~kg} / \mathrm{m}^{2} \\
\text { Women: }<5.7 \mathrm{~kg} / \mathrm{m}^{2}\end{array}$ & AWGS 2019 [26] \\
\hline & DXA (ASMI) & $\begin{array}{l}\text { Men: }<7.0 \mathrm{~kg} / \mathrm{m}^{2} \\
\text { Women: }<5.4 \mathrm{~kg} / \mathrm{m}^{2}\end{array}$ & AWGS 2019 [26] \\
\hline & $\begin{array}{l}\text { Calf circumference } \\
\text { (surrogate measure) }\end{array}$ & $\begin{array}{l}\text { Men: }<34 \mathrm{~cm} \\
\text { Women: }<33 \mathrm{~cm}\end{array}$ & AWGS 2019 [26] \\
\hline \multirow[t]{2}{*}{ Physical performance } & Usual gait speed & $<1.0 \mathrm{~m} / \mathrm{s}$ & AWGS 2019 [26] \\
\hline & $\begin{array}{l}\text { 5-times CST test }{ }^{a} \\
\text { (surrogate measure) }\end{array}$ & $\begin{array}{l}\geq 12 \mathrm{~s} \text { as a proxy for low gait } \\
\text { speed }(<1.0 \mathrm{~m} / \mathrm{s})\end{array}$ & AWGS 2019 [26] \\
\hline
\end{tabular}

${ }^{a}$ The use of a standardized protocol, such as the one from the American Academy or Orthotists \& Prosthetists is recommended. Abbreviations: ASMI Appendicular skeletal mass index (ASM adjusted for height), AWGS Asian Working Group for Sarcopenia, BIA Bioimpedance analysis, DXA Dual-energy X-ray absorptiometry, CST Chair Stand Test

important role as a surrogate measure of lower limb strength for older persons, particularly where the older patient has difficulties following accurately the protocol for hand grip strength measurements, or have joint pathology in their hands precluding the use of a dynamometer. A prospective cohort study of 4335 older people age $\geq 65$ living in the community in Japan reported a cut-off of $\geq 10$ s for 5 CST using receiver operating characteristic (ROC) curve analysis to maximize sensitivity and specificity in predicting future disability [54]. In view of the recognized ethnic variations in normative values for 5CST between Asia and North America populations [61], we will be adopting the 5 CST cut-off of $\geq 10$ s for our consensus statement.

Patients who screen positive by SARC-F and have low muscle strength would fulfill the criteria for possible/ probable sarcopenia. Lifestyle changes and education in terms of exercise and nutrition should be initiated at this point in the community and primary care settings $[9$, 26]. Where indicated, these patients should be referred for further assessment to confirm the diagnosis of sarcopenia and to identify underlying causes which may be reversible.

\section{Recommendation 4}

Diagnosis of confirmed sarcopenia should be based on the presence of low muscle strength and low muscle mass; for severe sarcopenia, low physical performance is also present in addition to low muscle strength and low muscle mass.

As per the EWGSOP2 and AWGS 2019 consensus, a diagnosis of sarcopenia should be based on the detection of low muscle strength and low muscle mass $[9,26]$. Muscle strength is prioritized as a primary determinant of sarcopenia as aging is associated with significantly greater declines in muscle strength and physical performance than in muscle mass $[1-3,62]$. Muscle strength has also been shown to predict adverse outcomes, such as falls, functional decline, cardiovascular disease and mortality in older adults [63-67] and reported to be the most reliable predictor of muscle function [9]. In a recent literature review initiated by the World Health Organisation (WHO), physical performance is separate from muscle function, and is defined as an objectively measured whole body function related with mobility [60]. As such, we recommend the assessment for low physical performance as a marker of severe sarcopenia, in the presence of both low muscle strength and low muscle mass. The three major causes of secondary sarcopenia are physical inactivity, malnutrition and diseases which lead to inflammation, chronic neurological disorder and musculoskeletal disorder [9], of which the first two are modifiable.

Physical inactivity, due to a sedentary lifestyle or prolonged bed rest, is associated with the development of sarcopenia in older adults [68-70]. Additionally, older age is often characterized by a loss of appetite and/or decreased food intake (anorexia of aging) that contributes to malnutrition, which in turn is associated with sarcopenia across the continuum of care $[49,71-76]$. There is a high prevalence of the risk of malnutrition among older adults in various settings (i.e., community [27\%], outpatient settings [31\%], hospitals [46\%], nursing homes and long-term care facilities [ 50\%]) [77]. In Singapore, 
approximately $30 \%$ of older adults are reported to be at nutritional risk in community and inpatient settings [78-80]. Importantly, the Singapore Longitudinal Aging Study reported that in Chinese older adults (65-90 years), malnutrition and risk of malnutrition were independently associated with sarcopenia after adjustment for age and gender [73].

When identifying malnutrition, we recommend the Global Leadership Initiative on Malnutrition's two-step model, which advocates risk screening using any validated nutrition screening tool (e.g., MNA-SF [81], NRS2002 [82] and MUST [83]), followed by diagnosis using at least one phenotypic (non-volitional weight loss, low body mass index or reduced muscle mass) and one etiological criterion (reduced food intake or assimilation, or inflammation, or disease burden) [84].

\section{Diagnosis of sarcopenia across the continuum of care Recommendation 5}

In community and outpatient settings, bioimpedance analysis can be used to determine low muscle mass. In the absence of other alternatives, calf circumference can be used as a surrogate measure of muscle mass in patients without edema and not suspected to have sarcopenic obesity. In inpatient settings, dualenergy X-ray absorptiometry can be used as the reference standard for measuring muscle mass.

We propose using bioimpedance analysis (BIA) to estimate appendicular skeletal muscle mass (ASM) in community and outpatient settings $[8,9]$ due to its affordability, portability and ease of use $[8,9,48,85]$. In the absence of BIA, calf circumference can be used as a surrogate measure of muscle mass $[9,25]$ as it is associated with poor physical strength and is predictive of physical performance and survival in older adults [86, 87]. Caution is required in patients suspected to have edema or sarcopenic obesity as the use of calf circumference in these settings will give a false-negative result. Recommended cut-off values for BIA and calf circumference to identify low muscle mass based on the AWGS 2019 are presented in Table 3.

For inpatients, several consensuses recommend dualenergy X-ray absorptiometry (DXA) to quantify ASM [8, $9,12,25]$ as it serves as a 'reference' standard due to a balance of accuracy and accessibility in clinical practice [88]. We suggest using the AWGS-recommended cut-off values for the diagnosis of low ASM using DXA in confirming the diagnosis of sarcopenia (Table 3).

\section{Recommendation 6}

Physical performance can be measured using the usual gait speed or by using the 5-times chair stand test with a cut-off of $\geq 12 \mathrm{~s}$ as a surrogate measure of gait speed of $1.0 \mathrm{~m} / \mathrm{s}$.
Physical performance has recently been defined as an objectively measured whole body function related with mobility [60] and can be assessed by a variety of methods. The usual gait speed is a pragmatic and reliable measure of physical performance [8, 9, 25]. Gait speed is predictive of adverse clinical outcomes, such as falls, functional decline, cognitive decline and mortality in Asian populations [89-92]. We suggest using the AWGS 2019-recommended cut-off value for measuring low gait speed in the 6-m walk test (Table 3). Low gait speed is an indicator of severe sarcopenia when combined with the presence of low muscle strength and low muscle mass [9].

When it is not feasible to measure the usual gait speed, we recommend the $5 \mathrm{CST}$ as a surrogate measure of gait speed in community-dwelling older adults [93]. Based on the study by Nishimura et al., a gait speed of $1.0 \mathrm{~m} / \mathrm{s}$ correlates with a cut-off of $\geq 12 \mathrm{~s}$ for 5 CST [93]; this is also recommended by AWGS 2019 [26].

\section{Interventions for muscle health \\ Recommendation 7}

Progressive resistance/weight-based training is effective for improving muscle mass, strength and physical performance.

In general, for older adults age 65 and above, more physical activity (frequency, duration and/or volume) leads to greater benefits as per the 2020 WHO Guidelines [94]. The International Clinical Practice Guidelines for Sarcopenia prescribes progressive RET as the firstline therapy for sarcopenia [25]. Similarly, the American College of Sport Medicine strongly recommends RET to increase strength and power in older adults [95]. Evidence has demonstrated the benefit of exercise training, especially RET for $\geq 3$ months, in improving muscle mass, strength and gait speed in older adults [12, 70, 96-98]. Additionally, higher RET volume (total repetitions [number] x external load [kg]) is associated with greater improvements in LBM, with every additional 10 sets of exercise performed per session leading to an expected gain of $0.5 \mathrm{~kg}$ in LBM [97]. With each incremental increase in exercise intensity from low $(<60 \% 1$ repetition maximum $[\mathrm{RM}])$ to low/moderate $(60-69 \% 1$ $\mathrm{RM})$, low/moderate $(60-69 \% \quad 1 \mathrm{RM})$ to moderate/ high (70-79\% 1-RM), and moderate/high (70-79\% 1-RM) to high $(>80 \% 1 \mathrm{RM})$, a $5.5 \%$ increase in strength is expected $[96,99,100]$.

Table 4 outlines an example of how a 12-week structured RET-based exercise program for older adults can be implemented in terms of specificity, overload and progression exercise prescription principles [95, 99, 101-104]. The application of moderate or greater intensity muscle strengthening exercises 2 or more days a week receives a strong recommendation with moderate 
Table 4 Example of a 12-week structured RET-based exercise program ${ }^{a}$

\begin{tabular}{|c|c|c|c|c|c|c|}
\hline Week & $1-2$ & $3-4$ & $5-6$ & $7-8$ & $9-10$ & $11-12$ \\
\hline Aim & \multicolumn{2}{|c|}{ Attain Adaptability } & \multicolumn{2}{|l|}{ Develop Muscle Bulk } & \multicolumn{2}{|l|}{ Build Strength } \\
\hline Type [101] & \multicolumn{3}{|c|}{ Postural stabilization, Body weight Closed chain exercises } & \multicolumn{3}{|c|}{ Free weights, open chain exercises } \\
\hline Frequency (alternate days per week) & $1-2$ & $1-2$ & 2 & 2 & $2-3$ & $2-3$ \\
\hline $\begin{array}{l}\text { b Intensity (number of repetitions to fatigue) } \\
{[101,102]}\end{array}$ & $\begin{array}{l}20 \\
\text { low }\end{array}$ & $\begin{array}{l}15 \\
\text { low }\end{array}$ & $\begin{array}{l}12 \\
\text { moderate }\end{array}$ & $\begin{array}{l}10 \\
\text { moderate }\end{array}$ & $\begin{array}{l}\text { 8-10 } \\
\text { moderate-high }\end{array}$ & $\begin{array}{l}6-8 \\
\text { high }\end{array}$ \\
\hline Volume (number of sets) & 1 & $1-2$ & 2 & $2-3$ & $2-3$ & 3 \\
\hline Specific muscle groups & \multicolumn{2}{|c|}{$\begin{array}{l}\text { Core: } \\
\text { Abdominals } \\
\text { Back } \\
\text { Chest } \\
\text { Proximal Stabilisers: } \\
\text { Shoulders } \\
\text { Hips } \\
\text { - Wall push ups } \\
\text { - Bench presses } \\
\text { - Crunches } \\
\text { - Lunges } \\
\text { - Mini Squats } \\
\text { - Bridging }\end{array}$} & \multicolumn{2}{|c|}{$\begin{array}{l}\text { Distal Peripherals: } \\
\text { Arms } \\
\text { Legs } \\
\text { Proximal Stabilisers: } \\
\text { Shoulders } \\
\text { Hips } \\
\text { Core: } \\
\text { Abdominals } \\
\text { Back } \\
\text { Chest } \\
\text { - Resistance Bands } \\
\text { - Weight Machine Stations } \\
\text { - Arm Ergometry } \\
\text { - Leg Pedal }\end{array}$} & \multicolumn{2}{|c|}{$\begin{array}{l}\text { Distal Peripheral: } \\
\text { Arms } \\
\text { Legs } \\
\text { Proximal Stabilisers: } \\
\text { Shoulders } \\
\text { Hips } \\
\text { Core: } \\
\text { Abdominals } \\
\text { Back } \\
\text { Chest } \\
\text { - Dumbbells } \\
\text { - Weight Machine Stations }\end{array}$} \\
\hline
\end{tabular}

\footnotetext{
${ }^{a}$ Adapted and modified from Peterson MD, Gordon PM. Resistance exercise for the aging adult: clinical implications and prescription guidelines. Am J Med 2011;124(3):194-8

${ }^{\mathrm{b}}$ Progression of intensity - initially, the intensity of the exercise (weight or resistance loading) may be increased when the subject can achieve $\geq 20$ repetitions in good form - indicative that current resistance is below the $60 \% 1 \mathrm{RM}$ threshold required for muscle strengthening [102, 103]. Progressively, the load can be adjusted higher to reflect higher intensity through the number of repetitions to fatigue or reduced ability to retain good form. Higher intensity RET can attain fatigue and should be stopped before strain of the training muscle
}

certainty of evidence by the WHO Guidelines 2020 [94]. The Borg scale (Table 5) allows individuals to rate their level of exertion during exercise and can be used as a simplified alternative to gauge exercise intensity $[104,105]$.

It is important to consider task-specific functional training in enhancing muscle health and function in older adults [102]. The principles of specificity, overload and progression should be applied similarly in the design. One example of such a program is the Lifestyle approach to reducing Falls through Exercise (LiFE), where strength training (with balance training) is embedded in daily activities [106]. This emphasis on functional balance and strength training is given strong recommendations with moderate certainty of evidence by the WHO Guidelines 2020 [94].

\section{Recommendation 8}

Adequate calorie and protein diet support muscle health for healthy community-dwelling older adults.

A total daily protein intake of at least $1.0-1.2 \mathrm{~g} / \mathrm{kg}$ body weight is recommended in healthy individuals $>65$ years of age [107]. In active, exercising healthy older adults, protein intake of $\geq 1.2 \mathrm{~g} / \mathrm{kg}$ body weight/day is advised [107]. In addition, even distribution of protein intake throughout the day may help ensure some degree of muscle protein synthesis (MPS) throughout the day [107-112]. However, to maximize MPS, crossing an anabolic threshold may be necessary. Some studies suggest a threshold of 25-30 g protein
Table 5 The RPE Borg Scale

\begin{tabular}{ll}
\hline Borg's Rating of Perceived Exertion (RPE) Scale \\
\hline Perceived Exertion Rating & Description of Exertion \\
\hline 6 & No exertion; sitting and resting \\
7 & Extremely light \\
8 & Very light \\
9 & \\
10 & Light \\
11 & \\
12 & Somewhat hard \\
13 & Hard \\
14 & \\
15 & Very hard \\
16 & \\
17 & Extremely hard \\
18 & Maximal exertion \\
19 & \\
20 & $\begin{array}{l}\text { a The scale is a guide as to how much older persons can push themselves } \\
\text { during the resistance-based exercises. Exercises can be stopped or modified } \\
\text { when the participants report perceived exertion levels beyond 15 or "Hard" on } \\
\text { the Borg scale [105] }\end{array}$
\end{tabular}


per meal [107], whereas others suggest $0.4 \mathrm{~g} / \mathrm{kg} / \mathrm{meal}$ of protein [108]. Since the ideal consumption pattern remains to be elucidated [107], clinicians should evaluate and adjust the nutritional interventions from time to time. An adequate intake of protein needs to be accompanied by appropriate energy intake of $30 \mathrm{kcal} / \mathrm{kg}$ body weight/day as recommended for older adults. This value should be individualized based on clinical and patient factors [27]. In Singapore, HCPs can utilize the online calculator from the Health Promotion Board to determine the energy values and nutrition composition of various foods [113].

The WHO recommends oral supplemental nutrition (from food fortification to ONS) plus dietary advice for older adults with undernutrition in the community setting [20]. In older adults with chronic conditions with or at risk of malnutrition, ONS are strongly recommended when dietary counselling and food fortification is insufficient to meet nutritional goals [27]. Limited evidence also suggests that high protein ONS with HMB (HPONS + HMB; $1.5 \mathrm{~g} /$ day) may increase muscle strength in the presence of resistance exercise in communitydwelling older women [114].

\section{Recommendation 9}

Supplementation of protein and calories, either via whole foods and/or high protein oral nutrition supplements, should be the primary focus of any nutrition interventions aimed at optimizing muscle health and recovery in hospitalized patients.

Older adults with acute or chronic disease require a dietary protein intake of $1.2-1.5 \mathrm{~g} / \mathrm{kg}$ body weight/day [107]. In severe illness, injury or severe malnutrition, up to $2.0 \mathrm{~g}$ protein/kg body weight/day may be necessary [107]. The total daily protein requirement can be divided evenly across three main meals to enable some degree of MPS throughout the day [107-112]. However, at least 25-30 g [107] or $0.4 \mathrm{~g}$ protein $/ \mathrm{kg}$ [108] would be required to maximize MPS to account for increased anabolic resistance, periods of energy deficit and loss due to first-pass effect during digestion $[107,111,115]$. Older people with severe kidney disease (estimated glomerular filtration rate $<30 \mathrm{~mL} / \mathrm{min} / 1.73 \mathrm{~m}^{2}$ ) and not on dialysis may need to limit protein intake [107]. In this scenario, the challenge lies in balancing the avoidance of excess protein intake to optimize renal health versus insufficient protein intake leading to protein energy wasting [116].

ONS may be offered to hospitalized patients to lower the risk of functional decline [27]. Upon meeting basic protein and caloric requirements with food, or when food intake alone is insufficient to meet increased nutritional requirements as specified above, additional supplementation may be considered using HP-ONS + HMB, HMB with arginine and glutamine (HMB-Arg-Glut) alone and/or leucine alone to improve muscle health. In older patients who are malnourished or at risk of malnutrition, limited evidence suggests that HP-ONS + HMB increases muscle strength [117] and LBM [118]. In contrast, a meta-analysis demonstrated that leucine supplementation significantly increases LBM and not muscle strength in patients with sarcopenia [119].

Some evidence suggests that the use of HMB 2-3g per day may help prevent muscle mass loss in older adults on prolonged bed rest [120,121]. Larger studies are required to confirm these findings.

\section{Recommendation 10}

Meeting the recommended daily intake of vitamin $D$ (600-800 IU) may improve muscle strength across the continuum of care and vitamin $\mathrm{D}$ deficiency should be treated.

Vitamin D is vital for maintaining normal muscle function. In patients with sarcopenia, a target serum vitamin $\mathrm{D}$ of $>30 \mu \mathrm{g} / \mathrm{L}$ is recommended to optimize outcomes. A recent study in Singapore, which recruited community-dwelling older adults who are not at risk of malnutrition, reported the prevalence of vitamin $\mathrm{D}$ insufficiency $(20-30 \mu \mathrm{g} / \mathrm{L})$ and deficiency $(<20 \mu \mathrm{g} / \mathrm{L})$ as 38.5 and $13.5 \%$, respectively [122].

At present, routine serum vitamin $\mathrm{D}$ testing in the general population is not recommended. However, vitamin D supplementation has a small beneficial effect on muscle strength [123] and a daily intake of 600-800 IU of vitamin D is recommended for older adults [124]. In patients $>65$ years who are vitamin D deficient, replacement with oral cholecalciferol 50,000 units weekly may be beneficial until the serum level is above $30 \mu \mathrm{g} / \mathrm{L}$ [125], particularly in the context of sarcopenia [126, 127].

\section{Recommendation 11}

A combination of physical activity and nutritional interventions is strongly recommended for optimal muscle health in patients with malnutrition or at risk of malnutrition.

Combining exercise and nutrition is an effective therapeutic intervention for sarcopenia [25] and for improving muscle health in older adults with or at risk of malnutrition [27]. Protein supplementation augments muscle mass and strength gains from prolonged RET in older adults [128]. A meta-analysis found that protein supplementation has a stronger effect in preventing loss of muscle mass and leg strength in older adults at risk of sarcopenia and frailty compared with RET alone [129]. There is also some evidence of the additive benefit of RET and vitamin D3 supplementation for muscle strength in older individuals [130]. In addition, a recent small, four-arm, randomized controlled trial in Japan demonstrated the synergistic effect of RET, protein and 
vitamin D supplementation in older adults with sarcopenia or dynapenia, with significant improvements in lower limb muscle quality and strength, when compared with exercise alone, nutritional supplementation alone or the control group [131]. A significant improvement in terms of appendicular lean muscle mass was also seen in subjects who started the trial with low muscle mass in the combined intervention group [131].

Performing exercise in close temporal proximity to the nutrition intervention or protein-rich meal has been shown to be beneficial for muscle anabolism [132]. Physical activity improves the sensitivity of MPS response to the provision of amino acids and reduces anabolic resistance. This enhanced response is sustained for days after resistance-based training [133].

\section{Overall management}

Recommendation 12

A multidisciplinary team (physicians, dietitians/nutritionists, physiotherapists, nurses and other relevant healthcare professionals) is essential for optimizing muscle health in all settings.

A multidisciplinary team (MDT) facilitates individualized and patient-centric management of muscle health [25] and has been shown to increase the frequency of evaluation of sarcopenia and implementation of rehabilitation nutrition in Japan [134]. In Singapore, geriatricians and rehabilitation medicine physicians routinely lead MDTs in hospital settings. Family physicians would be well poised to do the same in the community setting. Lifestyle, biological and psychosocial factors that influence muscle health should also be identified and managed by various HCPs [7], further iterating the importance of the MDT.

\section{Recommendation 13}

Patients and caregivers should be educated on the importance of combining physical activity and nutritional interventions for improving muscle health.

Patient and caregiver education should emphasize that the treatment for sarcopenia requires RET and optimal nutritional intake [25]. Improving patient awareness on the causes of and strategies to reverse or mitigate muscle impairment may address any misconceptions about sarcopenia as an inevitable consequence of aging and improve adherence to prescribed interventions [25]. In addition, acceptability of RET may be enhanced by knowledge that using low weights at higher velocity can also be beneficial [135] and is supported by the WHO 2020 Guidelines [94].

We suggest several population-based strategies to further encourage muscle health in Singapore (Table 6) [136].

\section{Recommendation 14}

Across all healthcare settings, urgent initiatives are required to raise awareness, educate and skill relevant healthcare professionals on screening, prevention and management of poor muscle health.

Considering the known gaps and lack of standardization in clinical practice [20, 23], HCPs across all healthcare settings need to be trained in the assessment of muscle strength, muscle mass and physical performance, and in the prevention and management of poor muscle health across all settings [51]. In this context, these recommendations can guide best practices among HCPs.

\section{Discussion}

To optimize muscle health in older adults in Singapore, we have proposed evidence-based practical guidance on screening, diagnosis and multi-modal interventions encompassing RET and nutrition across the continuum of care. Our concise and harmonized recommendations highlight the importance of a holistic multidisciplinary approach to muscle health in the older adults, and provides a unique, explicit, evidence-based progressive RET protocol as an intervention to improve muscle strength and mass. While tailored for the Singapore population, these recommendations may also be applicable in similar countries across Asia.

In the AWGS 2019 recommendations, we have noted that handgrip strength is the sole measure of strength [26]. For some older patients, they may not be able to operate the hand dynamometer to the required standard due to physical and/or cognitive limitations. Our inclusion of the 5 CST $\geq 10 \mathrm{~s}$ as a surrogate measure of lower limb strength based on Asian data from Makizako et al. [54] will facilitate the measurement of strength in this group of patients. We believe that this small but important difference will contribute to a more streamlined and comprehensive assessment of Asian patients at risk of poor muscle health.

In addition, our consensus statement on physical interventions can be utilized as part of a cost-effective targeted communication campaign promoting physical activity in older adults, and would be in keeping with the recommendations of the WHO Guidelines 2020 [94] as well as the WHO Global Action Plan on Physical Activity 2018-2030 [137].

In order to implement these recommendations in clinical practice, comprehensive education of HCPs on the importance of muscle health and potential deleterious consequences of sarcopenia is required. Urgent initiatives are hence needed to train relevant HCPs to screen and diagnose sarcopenia; utilize evidence-based exercise and nutrition interventions 
Table 6 Suggested population-based strategies to promote muscle health in Singapore [136]

\begin{tabular}{|c|c|}
\hline $\begin{array}{l}\text { Population-based } \\
\text { strategies }\end{array}$ & Examples relevant to promoting muscle health \\
\hline Screening and outreach & $\begin{array}{l}\text { - Identify early muscle loss by detecting deterioration in usual physical function or strength, during screening events or } \\
\text { visits to polyclinics or general practice clinics. } \\
\text { - Improve HCP awareness of muscle loss identification by mere observation of general body muscle bulk in older } \\
\text { individuals over time. }\end{array}$ \\
\hline Referral and follow-up & $\begin{array}{l}\text { - Encourage older persons to focus on resistance exercises in order to build muscle strength and mass, e.g., in fitness } \\
\text { corners, resistance exercise parks and senior-friendly gyms. } \\
\text { - Active referral of older persons to available community resources, e.g., day rehabilitation centres, as appropriate. } \\
\text { - Consider referral to a dietician, if the older adult is malnourished and might require more complex interventions. }\end{array}$ \\
\hline $\begin{array}{l}\text { Health teaching and } \\
\text { coaching }\end{array}$ & $\begin{array}{l}\text { - Emphasize the importance of optimal calories ( } 30 \mathrm{kcal} / \mathrm{kg} \text { body weight/day) and protein ( } \geq 1.2 \mathrm{~g} / \mathrm{kg} \text { body weight/day) } \\
\text { in older adults. } \\
\text { - Promote more active uptake of resistance exercise by advocating for gradual progression with sufficient intensity. }\end{array}$ \\
\hline $\begin{array}{l}\text { Consultation and } \\
\text { collaboration }\end{array}$ & $\begin{array}{l}\text { - Collaborate with organizations to include basic } \\
\text { nursing skills requirement for foreign domestic }\end{array}$ \\
\hline $\begin{array}{l}\text { Advocacy and policy } \\
\text { development }\end{array}$ & $\begin{array}{l}\text { - Make government subsidies available via the Senior Mobility Fund to support rehabilitation programs at home (e.g., } \\
\text { telerehabilitation equipment, weights and resistance bands). } \\
\text { - Currently, eligible patients can already access subsidy for ONS under the Senior Mobility Fund. }\end{array}$ \\
\hline Social marketing & $\begin{array}{l}\text { - Link exercise and nutrition for muscle health with campaigns related to bone health - i.e., 'to prevent fractures and } \\
\text { falls, take calcium for bone and protein for muscle.' }\end{array}$ \\
\hline
\end{tabular}

for muscle health; and monitor the outcomes of these interventions.

We acknowledge that our recommendations are based on a narrative review and should be used in this context. However, we have included the latest available literature, international guidelines and results of systematic reviews on muscle health to guide our recommendations.

\section{Conclusion}

The rapidly aging population in Singapore and Asia necessitates the prioritization of muscle health from a public health perspective, and strong collaboration among various stakeholders, including clinicians, professional societies and policy makers are urgently required. Therefore, we hope that these consensus recommendations on muscle health can serve as a holistic platform for the comprehensive advancement of muscle health, and spur much needed new research in this area to fill the gaps of knowledge that still remains.

\section{Abbreviations}

5CST: 5-times chair stand test; ASM: Appendicular skeletal muscle mass; ASMI: Appendicular skeletal muscle index; AWGS: Asian Working Group for Sarcopenia; BIA: Bioimpedance analysis; DXA: Dual-energy X-ray absorptiometry; EWGSOP: European Working Group on Sarcopenia in Older People; HCP: Healthcare professional; HMB: $\beta$-hydroxy $\beta$-methylbutyrate; HPONS: High protein oral nutritional supplements; LBM: Lean body mass; MDT: Multidisciplinary team; MPS: Muscle protein synthesis; ONS: Oral nutritional supplements; RET: Resistance exercise training; RM: Repetition maximum; WHO: World Health Organization

\section{Acknowledgments}

We thank Dr. Laura Tay from the Society for Geriatric Medicine Singapore for her participation and contribution during the consensus meeting; Ms. Lee Sin $\mathrm{Yi}$, the President of the Singapore Physiotherapy Association for her valuable input and review of this manuscript; the Society of Rehabilitation Medicine Singapore, and the Singapore Nutrition and Dietetics Association for their review and endorsement of this manuscript. Editorial assistance for this manuscript was provided by Yulyana Yulyana and Aishwarya Sridharan from In Vivo Communications (Asia) Pte Ltd.

\section{Authors' contributions}

STHC chaired the first face-to-face meeting between all members of the multidisciplinary working group, led and facilitated all subsequent consensus seeking discussions via e-mail. All authors (STHC, GK, CCHL, TPN, FO, JT, NCT, SLT) participated in the consensus meeting, made substantial contributions to the review of evidence and formulation of the recommendations, were involved in the preparation of the manuscript, and provided critical revision for intellectual content and final approval for submission. All authors have also agreed to be personally accountable for the accuracy and integrity of the manuscript submitted.

\section{Author's information}

STH Chew is a full time Senior Consultant Geriatrician, providing both inpatient service for acute admission of geriatric patients, and out-patient geriatric clinical services in a large teaching public general hospital in Singapore. He is a Fellow of the Royal College of Physicians of Edinburgh, and a Fellow of the Academy of Medicine Singapore. He is also an Adjunct Associate Professor of Medicine, Yong Loo Lin School of Medicine, National University of Singapore. STH Chew is the Principal Investigator for one of the largest randomised controlled clinical trial on the impact of nutrition on clinical outcomes in community dwelling independently ambulant older adults at risk of undernutrition in the Asia Pacific region [ClinicalTrials.gov Identifier: NCT03245047], which has recently concluded.

\section{Funding}

The consensus meeting was initiated and supported by Abbott Laboratories (Singapore) Pte Ltd. All members of the working group did not receive any incomes or honorarium, from Abbott Laboratories (Singapore) Pte Ltd. or any other organizations, for any of the tasks involved in the preparation of this manuscript or for attending the meeting of the group. For the development of the consensus manuscript, support from Abbott Laboratories (Singapore) Pte Ltd. was strictly limited to editorial services provided by the medical writer (see acknowledgements). Abbott Laboratories (Singapore) Pte Ltd. played no role in the preparation or approval of this manuscript.

Availability of data and materials Not applicable. 


\section{Declarations}

\section{Ethics approval and consent to participate}

Not applicable.

\section{Consent for publication}

Not applicable.

\section{Competing interests}

STHC has received honoraria for speaking engagement and travel grants from Abbott. GK, CCHL, TPN, FO, JT, NCT and SLT declared no conflicts of interest.

\section{Author details}

${ }^{1}$ Department of Geriatric Medicine, Changi General Hospital, 2 Simei Street 3, Singapore 529889, Singapore. ${ }^{2}$ Society for Geriatric Medicine Singapore, Singapore, Singapore. ${ }^{3}$ Department of Rehabilitation, National University Hospital, Singapore, Singapore. ${ }^{4}$ Singapore Nutrition and Dietetics Association, Singapore, Singapore. ${ }^{5}$ Yong Loo Lin School of Medicine, National University of Singapore, Singapore, Singapore. ${ }^{6}$ Mount Elizabeth Novena Hospital, Singapore, Singapore. ${ }^{7}$ Department of Research, SingHealth Polyclinics, Singapore, Singapore. ${ }^{8}$ Department of Rehabilitation Medicine, Tan Tock Seng Hospital, Singapore, Singapore. ${ }^{9}$ Society of Rehabilitation Medicine, Singapore, Singapore.

\section{Received: 26 June 2020 Accepted: 22 April 2021}

\section{Published online: 17 May 2021}

\section{References}

1. Marzetti E, Hwang AC, Tosato M, et al. Age-related changes of skeletal muscle mass and strength among Italian and Taiwanese older people: results from the Milan EXPO 2015 survey and the I-Lan longitudinal aging study. Exp Gerontol. 2018;102:76-80.

2. Mitchell WK, Williams J, Atherton P, et al. Sarcopenia, dynapenia, and the impact of advancing age on human skeletal muscle size and strength; a quantitative review. Front Physiol. 2012;3:260.

3. Landi F, Calvani R, Tosato M, et al. Age-related variations of muscle mass, strength, and physical performance in community-dwellers: results from the Milan EXPO survey. J Am Med Dir Assoc. 2017;18:88.e17-24.

4. Argilés JM, Campos N, Lopez-Pedrosa JM, et al. Skeletal muscle regulates metabolism via interorgan crosstalk: roles in health and disease. J Am Med Dir Assoc. 2016;17:789e796.

5. Demling $\mathrm{RH}$. Nutrition, anabolism, and the wound healing process: an overview. Eplasty. 2009;9:e9.

6. Prado CM, Purcell SA, Alish C, et al. Implications of low muscle mass across the continuum of care: a narrative review. Ann Med. 2018;50(8):675-93.

7. Tieland M, Trouwborst I, Clark BC. Skeletal muscle performance and ageing. J Cachexia Sarcopenia Muscle. 2018;9(1):3-19. https://doi.org/10.1002/ jcsm. 12238.

8. Chen LK, Liu LK, Woo J, et al. Sarcopenia in Asia: consensus report of the Asian working Group for Sarcopenia. J Am Med Dir Assoc. 2014;15:95-101.

9. Cruz-Jentoft AJ, Bahat G, Bauer J, et al. Sarcopenia: revised European consensus on definition and diagnosis. Age Ageing. 2019;48:16-31.

10. Arai H, Wakabayashi H, Yoshimura Y, Yamada M, Kim H, Harada A. Chapter 4 treatment of sarcopenia. Geriatr Gerontol Int. 2018;18(Suppl 1):28-44. https://doi.org/10.1111/ggi.13322.

11. Shafiee G, Keshtkar A, Soltani A, Ahadi Z, Larijani B, Heshmat R. Prevalence of sarcopenia in the world: a systematic review and meta- analysis of general population studies. J Diabetes Metab Disord. 2017;16(1):21. https:// doi.org/10.1186/s40200-017-0302-x.

12. Cruz-Jentoft AJ, Landi F, Schneider SM, Zuniga C, Arai H, Boirie Y, et al. Prevalence of and interventions for sarcopenia in ageing adults: a systematic review. Report of the international sarcopenia initiative (EWGSOP and IWGS). Age Ageing. 2014;43(6):748-59. https://doi.org/10.1093/ageing/afu115.

13. Welch C, Hassan-Smith Z, Greig CA, et al. Acute sarcopenia secondary to hospitalisation - an emerging condition affecting older adults. Aging Dis. 2018;9:151-64

14. Tan LF, Lim ZY, Choe R, et al. Screening for frailty and sarcopenia among older persons in medical outpatient clinics and its associations with healthcare burden. J Am Med Dir Assoc. 2017;18:583-7.
15. Tay L, Ding $Y Y$, Leung BP, et al. Sex-specific differences in risk factors for sarcopenia amongst community-dwelling older adults. Age (Dordr). 2015;37:121.

16. Fung FY, Koh YLE, Malhotra $R$, et al. Prevalence of and factors associated with sarcopenia among multi-ethnic ambulatory older Asians with type 2 diabetes mellitus in a primary care setting. BMC Geriatr. 2019;19(1):122.

17. Chew STH, Tey SL, Oliver J, et al. P289 prevalence of sarcopenia and associated characteristics in community-dwelling older adults who are at risk of malnutrition in Singapore. J Frailty Aging. 2020;9(S1):S46-179.

18. Tey SL, Chew STH, How CH, et al. Factors associated with muscle mass in community-dwelling older people in Singapore: findings from the SHIELD study. PLoS One. 2019;14(10):e0223222.

19. Ministry of Health 2019 Budget Speech. https://www.moh.gov.sg/newshighlights/details/opening-speech-by-mr-gan-kim-yong-minister-for-healthfor-the-parliamentary-debate-on-eldershield-review-committee-report-10july-2018. Accessed 26 July 2019.

20. World Health Organization. Integrated care for older people. Guidelines on community-level interventions to manage declines in intrinsic capacity. 2017. Available from: https://apps.who.int/iris/handle/10665/258981.

21. Nakahara S, Wakabayashi H, Maeda K, et al. Sarcopenia and cachexia evaluation in different healthcare settings: a questionnaire survey of health professionals. Asia Pac J Clin Nutr. 2018:27:167-75.

22. Deutz NEP, Ashurst I, Ballesteros MD, Bear DE, Cruz-Jentoft AJ, Genton L, et al. The underappreciated role of low muscle mass in the management of malnutrition. J Am Med Dir Assoc. 2019;20(1):22-7. https://doi.org/10.1016/j. jamda.2018.11.021.

23. Bruyère $O$, Beaudart $C$, Reginster JY, Buckinx F, Schoene $D$, Hirani V, et al. Assessment of muscle mass, muscle strength and physical performance in clinical practice: an international survey. Eur Geriatr Med. 2016;7(3):243-6. https://doi.org/10.1016/j.eurger.2015.12.009.

24. Reijnierse EM, de van der Schueren MAE, Trappenburg MC, Doves M, Meskers CGM, Maier AB. Lack of knowledge and availability of diagnostic equipment could hinder the diagnosis of sarcopenia and its management PLoS One. 2017;12(10):e0185837. https://doi.org/10.1371/journal.pone.01 85837.

25. Dent E, Morley JE, Cruz-Jentoft AJ, Arai H, Kritchevsky SB, Guralnik J, et al. International clinical practice guidelines for sarcopenia (ICFSR): screening, diagnosis and management. J Nutr Health Aging. 2018;22(10):1148-61. https://doi.org/10.1007/s12603-018-1139-9.

26. Chen LK, Woo J, Assantachai P, Auyeung TW, Chou MY, lijima K, et al. Asian working Group for Sarcopenia: 2019 consensus update on sarcopenia diagnosis and treatment. J Am Med Dir Assoc. 2020;21(3):300-7. https://doi. org/10.1016/j.jamda.2019.12.012.

27. Volkert D, Beck AM, Cederholm T, Cruz-Jentoft A, Goisser S, Hooper L, et al. ESPEN guideline on clinical nutrition and hydration in geriatrics. Clin Nutr. 2019;38(1):10-47. https://doi.org/10.1016/j.clnu.2018.05.024

28. Beaudart C, Zaaria M, Pasleau F, et al. Health outcomes of sarcopenia: a systematic review and meta-analysis. PLoS One. 2017;12:e0169548.

29. Beaudart $C$, McCloskey $E$, Bruyère $O$, et al. Sarcopenia in daily practice: assessment and management. BMC Geriatr. 2016;16:170.

30. Koh ASM, Wong J, Yew WY, Chua SJM, Huang F, Leng S, et al. Sarcopenia and vascular function among community elderly. J Am Coll Cardiol. 2017; 69(11):2051. https://doi.org/10.1016/S0735-1097(17)35440-2.

31. Tanimoto $Y$, Watanabe $M$, Sun $W$, Sugiura $Y$, Tsuda $Y$, Kimura $M$, et al. Association between sarcopenia and higher-level functional capacity in daily living in community-dwelling elderly subjects in Japan. Arch Gerontol Geriatr. 2012;55(2):e9-e13. https://doi.org/10.1016/j.archger.2 012.06.015.

32. Tyrovolas S, Koyanagi A, Olaya B, et al. The role of muscle mass and body fat on disability among older adults: a cross-national analysis. Exp Gerontol. 2015;69:27-35.

33. Tanimoto $Y$, Watanabe M, Sun W, Sugiura $Y$, Hayashida I, Kusabiraki T, et al. Sarcopenia and falls in community-dwelling elderly subjects in Japan: defining sarcopenia according to criteria of the European working group on sarcopenia in older people. Arch Gerontol Geriatr. 2014;59(2):295-9. https:// doi.org/10.1016/j.archger.2014.04.016

34. Yamada M, Nishiguchi S, Fukutani N, Tanigawa T, Yukutake T, Kayama H, et al. Prevalence of sarcopenia in community-dwelling Japanese older adults. J Am Med Dir Assoc. 2013;14(12):911-5. https://doi.org/10.1016/j.ja mda.2013.08.015.

35. Tanimoto $Y$, Watanabe $M$, Sun $W$, Tanimoto $K$, Shishikura $K$, Sugiura $Y$, et al. Association of sarcopenia with functional decline in community-dwelling 
elderly subjects in Japan. Geriatr Gerontol Int. 2013;13(4):958-63. https://doi. org/10.1111/ggi.12037.

36. Landi F, Cruz-Jentoft AJ, Liperoti $R$, et al. Sarcopenia and mortality risk in frail older persons aged 80 years and older: results from ilSIRENTE study. Age Ageing. 2013;42:203-9.

37. Yuki A, Ando F, Otsuka R, Shimokata H. Sarcopenia based on the Asian working Group for Sarcopenia criteria and all-cause mortality risk in older Japanese adults. Geriatr Gerontol Int. 2017;17(10):1642-7. https://doi.org/1 $0.1111 /$ ggi.12946.

38. Yalcin A, Aras S, Atmis $V$, et al. Sarcopenia and mortality in older people living in a nursing home in Turkey. Geriatr Gerontol Int. 2017;17:1118-24.

39. Wu TY, Liaw CK, Chen FC, Kuo KL, Chie WC, Yang RS. Sarcopenia screened with SARC-F questionnaire is associated with quality of life and 4-year mortality. J Am Med Dir Assoc. 2016;17(12):1129-35. https://doi.org/10.1016/ j.jamda.2016.07.029.

40. Yang M, Hu X, Wang H, Zhang L, Hao Q, Dong B. Sarcopenia predicts readmission and mortality in elderly patients in acute care wards: a prospective study. J Cachexia Sarcopenia Muscle. 2017;8(2):251-8. https:// doi.org/10.1002/jcsm. 12163.

41. Keevil V, Mazzuin Razali R, Chin AV, et al. Grip strength in a cohort of older medical inpatients in Malaysia: a pilot study to describe the range, determinants and association with length of hospital stay. Arch Gerontol Geriatr. 2013;56:155-9.

42. Tang TC, Hwang AC, Liu LK, Lee WJ, Chen LY, Wu YH, et al. FNIH-defined sarcopenia predicts adverse outcomes among community-dwelling older people in Taiwan: results from I-Lan longitudinal aging study. J Gerontol A Biol Sci Med Sci. 2018;73(6):828-34. https://doi.org/10.1093/gerona/glx148.

43. Zhang X, Zhang W, Wang C, Tao W, Dou Q, Yang Y. Sarcopenia as a predictor of hospitalization among older people: a systematic review and meta-analysis. BMC Geriatr. 2018;18(1):188. https://doi.org/10.1186/s12877-01 8-0878-0.

44. Cheung JTK, Yu R, Wu Z, Wong SYS, Woo J. Geriatric syndromes, multimorbidity, and disability overlap and increase healthcare use among older Chinese. BMC Geriatr. 2018;18(1):147. https://doi.org/10.1186/s12877018-0840-1.

45. Lo YC, Wahlqvist ML, Huang YC, et al. Medical costs of a low skeletal muscle mass are modulated by dietary diversity and physical activity in communitydwelling older Taiwanese: a longitudinal study. Int I Behav Nutr Phys Act. 2017;14(1):31. https://doi.org/10.1186/s12966-017-0487-x.

46. Sousa AS, Guerra RS, Fonseca I, et al. Financial impact of sarcopenia on hospitalization costs. Eur J Clin Nutr. 2016;70:1046-51.

47. Grimby G, Saltin B. The ageing muscle. Clin Physiol. 1983;3:209-18.

48. Janssen I, Heymsfield SB, Baumgartner RN, Ross R. Estimation of skeletal muscle mass by bioelectrical impedance analysis. J Appl Physiol (1985). 2000;89:465-71.

49. Vandewoude MF, Alish CJ, Sauer AC, Hegazi RA. Malnutrition-sarcopenia syndrome: is this the future of nutrition screening and assessment for older adults? J Aging Res. 2012;2012:651570.

50. English KL, Paddon-Jones D. Protecting muscle mass and function in older adults during bed rest. Curr Opin Clin Nutr Metab Care. 2010;13:34-9.

51. Bauer J, Morley JE, Schols AMWJ, et al. Sarcopenia: a time for action. An SCWD position paper. J Cachexia Sarcopenia Muscle. 2019;10(5):956-61.

52. Nakazono $\mathrm{T}$, Kamide $\mathrm{N}$, Ando $\mathrm{M}$. The reference values for the chair stand test in healthy Japanese older people: determination by meta-analysis. J Phys Ther Sci. 2014;26(11):1729-31. https://doi.org/10.1589/jpts.26.1729.

53. Malmstrom TK, Miller DK, Simonsick EM, et al. SARC-F: a symptom score to predict persons with sarcopenia at risk for poor functional outcomes. J Cachexia Sarcopenia Muscle. 2016;7:28-36.

54. Makizako H, Shimada H, Doi T, et al. Predictive cutoff values of the fivetimes sit-to-stand test and the timed "up \& go" test for disability incidence in older people dwelling in the community. Phys Ther. 2017; 97(4):417-24.

55. Cao L, Chen S, Zou C, Ding X, Gao L, Liao Z, et al. A pilot study of the SARC$F$ scale on screening sarcopenia and physical disability in the Chinese older people. J Nutr Health Aging. 2014;18(3):277-83. https://doi.org/10.1007/s12 603-013-0410-3.

56. Ida S, Murata K, Nakadachi D, et al. Development of a Japanese version of the SARC-F for diabetic patients: an examination of reliability and validity. Aging Clin Exp Res. 2017;29:935-42.

57. Tanaka S, Kamiya K, Hamazaki N, Matsuzawa R, Nozaki K, Maekawa E, et al. Utility of SARC-F for assessing physical function in elderly patients with cardiovascular disease. J Am Med Dir Assoc. 2017;18(2):176-81. https://doi. org/10.1016/j.jamda.2016.10.019.

58. Woo J, Leung J, Morley JE. Validating the SARC-F: a suitable community screening tool for sarcopenia? J Am Med Dir Assoc. 2014;15:630e634.

59. Ida S, Kaneko R, Murata K. SARC-F for screening of sarcopenia among older adults: a meta-analysis of screening test accuracy. J Am Med Dir Assoc. 2018;19(8):685-9. https://doi.org/10.1016/j.jamda.2018.04.001.

60. Beaudart C, Rolland Y, Cruz-Jentoft AJ, Bauer JM, Sieber C, Cooper C, et al. Assessment of muscle function and physical performance in daily clinical practice: a position paper endorsed by the European Society for Clinical and Economic Aspects of osteoporosis, osteoarthritis and musculoskeletal diseases (ESCEO). Calcif Tissue Int. 2019;105(1):1-14. https://doi.org/10.1007/ s00223-019-00545-W.

61. Aoyagi K, Ross PD, Nevitt MC, et al. Comparison of performance-based measures among native Japanese, Japanese-Americans in Hawaii and Caucasian women in the United States, ages 65 years and over: a crosssectional study. BMC Geriatr. 2001;1:3.

62. Auyeung TW, Lee SW, Leung J, et al. Age-associated decline of muscle mass, grip strength and gait speed: a 4-year longitudinal study of 3018 community-dwelling older Chinese. Geriatr Gerontol Int. 2014;14(Suppl 1): 76-84. https://doi.org/10.1111/ggi.12213.

63. Leong DP, Teo KK, Rangarajan S, et al. Prognostic value of grip strength: findings from the prospective urban rural epidemiology (PURE) study. Lancet. 2015;386:266-73.

64. Kim YH, Kim Kl, Paik NJ, Kim KW, Jang HC, Lim JY. Muscle strength: a better index of low physical performance than muscle mass in older adults. Geriatr Gerontol Int. 2016;16(5):577-85. https://doi.org/10.1111/ggi.12514.

65. Schaap LA, Koster A, Visser M. Adiposity, muscle mass, and muscle strength in relation to functional decline in older persons. Epidemiol Rev. 2013;35:51-65.

66. Schaap LA, van Schoor NM, Lips P, Visser M. Associations of sarcopenia definitions, and their components, with the incidence of recurrent falling and fractures: the longitudinal aging study Amsterdam. J Gerontol A Biol Sci Med Sci. 2018;73(9):1199-204. https://doi.org/10.1093/gerona/gl×245.

67. Taniguchi Y, Fujiwara Y, Murayama H, Yokota I, Matsuo E, Seino S, et al. Prospective study of trajectories of physical performance and mortality among community-dwelling older Japanese. J Gerontol A Biol Sci Med Sci. 2016;71(11):1492-9. https://doi.org/10.1093/gerona/glw029.

68. Marzetti CR, Tosato $M$, Cesari $M$, et al. Physical activity and exercise as countermeasures to physical frailty and sarcopenia. Aging Clin Exp Res. 2017;29(1):35-42. https://doi.org/10.1007/s40520-016-0705-4.

69. Mijnarends DM, Koster A, Schols JM, et al. Physical activity and incidence of sarcopenia: the population-based AGES-Reykjavik study. Age Ageing. 2016; 45(5):614-20. https://doi.org/10.1093/ageing/afw090.

70. Steff M, Bohannon RW, Sontakova L, Tufano JJ, Shiells K, Holmerova I. Relationship between sarcopenia and physical activity in older people: a systematic review and meta-analysis. Clin Interv Aging. 2017;12:835-45. https://doi.org/10.2147/CIA.S132940.

71. Landi F, Calvani R, Tosato M, et al. Anorexia of aging: risk factors, consequences, and potential treatments. Nutrients. 2016;8:69.

72. Liguori I, Russo G, Aran L, et al. Sarcopenia: assessment of disease burden and strategies to improve outcomes. Clin Interv Aging. 2018;13:913-27.

73. Lu Y, Karagounis LG, Ng TP, et al. Systemic and metabolic signature of sarcopenia in community-dwelling older adults. J Gerontol A Biol Sci Med Sci. 2019. https://doi.org/10.1093/gerona/glz001.

74. Hai S, Cao L, Wang H, Zhou J, Liu P, Yang Y, et al. Association between sarcopenia and nutritional status and physical activity among communitydwelling Chinese adults aged 60 years and older. Geriatr Gerontol Int. 2017; 17(11):1959-66. https://doi.org/10.1111/ggi.13001.

75. Hu X, Zhang L, Wang H, Hao Q, Dong B, Yang M. Malnutrition-sarcopenia syndrome predicts mortality in hospitalized older patients. Sci Rep. 2017; 7(1):3171. https://doi.org/10.1038/s41598-017-03388-3.

76. Reijnierse EM, Trappenburg MC, Leter MJ, Blauw GJ, de van der Schueren MAE, Meskers CGM, et al. The association between parameters of malnutrition and diagnostic measures of sarcopenia in geriatric outpatients. PLoS One. 2015; 10(8):e0135933. https://doi.org/10.1371/journal.pone.0135933.

77. Cereda E, Pedrolli C, Klersy C, et al. Nutritional status in older persons according to healthcare setting: a systematic review and meta-analysis of prevalence data using MNA ${ }^{\oplus}$. Clin Nutr. 2016;35:1282-90.

78. Lim SL, Ong KC, Chan YH, et al. Malnutrition and its impact on cost of hospitalization, length of stay, readmission and 3-year mortality. Clin Nutr. 2012;31(3):345-50. https://doi.org/10.1016/j.cInu.2011.11.001. 
79. Wei K, Nyunt MS, Gao Q, et al. Association of frailty and malnutrition with long-term functional and mortality outcomes among community-dwelling older adults: results from the Singapore longitudinal aging study 1. JAMA Netw Open. 2018;1(3):e180650. https://doi.org/10.1001/jamanetworkopen.2 018.0650 .

80. Yap KB, Niti M, Ng TP. Nutrition screening among community-dwelling older adults in Singapore. Singap Med J. 2007;48(10):911-6.

81. Rubenstein LZ, Harker JO, Salvá A, et al. Screening for undernutrition in geriatric practice: developing the short-form mini-nutritional assessment (MNA-SF). J Gerontol A Biol Sci Med Sci. 2001;56(6):M366-72.

82. Kondrup J, Rasmussen HH, Hamberg O. Stanga Z; ad hoc ESPEN working group. Nutritional risk screening (NRS 2002): a new method based on an analysis of controlled clinical trials. Clin Nutr. 2003;22(3):321-36.

83. Elia M. Nutritional screening of adults: a multidisciplinary responsibility. Development and use of the Malnutrition Universal Screening Tool ('MUST') for adults. https://www.bapen.org.uk/pdfs/must/must-report.pdf. Accessed on 7 Oct 2019

84. Cederholm T, Jensen GL, Correia MITD, et al. GLIM criteria for the diagnosis of malnutrition - a consensus report from the global clinical nutrition community. Clin Nutr. 2019;38:1-9.

85. Tosato M, Marzetti E, Cesari M, Savera G, Miller RR, Bernabei R, et al. Measurement of muscle mass in sarcopenia: from imaging to biochemical markers. Aging Clin Exp Res. 2017;29(1):19-27. https://doi.org/10.1007/s4052 0-016-0717-0.

86. Landi F, Onder G, Russo A, et al. Calf circumference, frailty and physical performance among older adults living in the community. Clin Nutr. 2014; 33:539-44.

87. Kim S, Kim M, Lee Y, et al. Calf circumference as a simple screening marker for diagnosing sarcopenia in older Korean adults: the Korean frailty and aging cohort study (KFACS). J Korean Med Sci. 2018;33:e151.

88. Buckinx F, Landi F, Cesari M, et al. Pitfalls in the measurement of muscle mass: a need for a reference standard. J Cachexia Sarcopenia Muscle. 2018;9:269-78.

89. Hsu CL, Liang CK, Liao MC, et al. Slow gait speed as a predictor of 1-year cognitive decline in a veterans' retirement community in southern Taiwan. Geriatr Gerontol Int. 2017;17(Suppl 1):14-9.

90. Huang TY, Liang CK, Shen HC, et al. Gait speed rather than dynapenia is a simple indicator for complex care needs: a cross-sectional study using minimum data det. Sci Rep. 2017;7:8418.

91. Nakamoto M, Otsuka R, Yuki A, et al. Higher gait speed and smaller sway area decrease the risk for decline in higher-level functional capacity among middle-aged and elderly women. Arch Gerontol Geriatr. 2015;61:429-36.

92. Zhao W, Ukawa S, Tsushita K, Kawamura T, Wakai K, Ando M, et al. Association of gait speed with mortality among the Japanese elderly in the new integrated suburban seniority investigation project: a prospective cohort study. Age Ageing. 2015;44(1):153-7. https://doi.org/10.1093/a geing/afu121.

93. Nishimura T, Arima K, Okabe T, et al. Usefulness of chair stand time as a surrogate of gait speed in diagnosing sarcopenia. Geriatr Gerontol Int. 2017; 17:659-61.

94. World Health Organization. WHO guidelines on physical activity and sedentary behaviour. Geneva: World Health Organization; 2020. Available from: https:// www.ncbi.nlm.nih.gov/books/NBK566045/. Accessed 22 Feb 2021

95. American College of Sports Medicine. American College of Sports Medicine position stand. Exercise and physical activity for older adults. Med Sci Sports Exerc. 2009:41:1510-30.

96. Peterson MD, Rhea MR, Sen A, Gordon PM. Resistance exercise for muscular strength in older adults: a meta-analysis. Ageing Res Rev. 2010;9(3):226-37. https://doi.org/10.1016/j.arr.2010.03.004.

97. Peterson MD, Sen A, Gordon PM. Influence of resistance exercise on lean body mass in aging adults: a meta-analysis. Med Sci Sports Exerc. 2011;43(2): 249-58. https://doi.org/10.1249/MSS.0b013e3181eb6265.

98. Yoshimura Y, Wakabayashi H, Yamada M, et al. Interventions for treating sarcopenia: a systematic review and meta-analysis of randomized controlled studies. J Am Med Dir Assoc. 2017;18:553.e1-553.e16.

99. Law TD, Clark LA, Clark BC. Resistance exercise to prevent and manage sarcopenia and dynapenia. Annu Rev Gerontol Geriatr. 2016;36(1):205-28. https://doi.org/10.1891/0198-8794.36.205.

100. Beckwée D, Delaere A, Aelbrecht S, et al. Exercise interventions for the prevention and treatment of sarcopenia. A systematic umbrella review. J Nutr Health Aging. 2019;23(6):494-502. https://doi.org/10.1007/s12603-01 9-1196-8.
101. Peterson MD, Gordon PM. Resistance exercise for the aging adult: clinical implications and prescription guidelines. Am J Med. 2011;124(3):194-8.

102. Avers D, Brown M. White paper: strength training for the older adult. J Geriatr Phys Ther. 2009;32:148-52.

103. Willoughby DS. Current comments are official statements by the American College of Sports Medicine concerning topics of interest to the public at large. Indianapolis: American College of Sports Medicine; 2015. Resistance Training and the Older Adult ACSM Current Comment

104. Borg G. Borg's perceived exertion and pain scales. Champaign: Human Kinetics; 1998.

105. Borg GA. Psychophysical bases of perceived exertion. Med Sci Sports Exerc. 1982;14(5):377-81.

106. Clemson L, Singh MF, Bundy A, Cumming RG, Weissel E, Munro J, et al. LiFE pilot study: a randomised trial of balance and strength training embedded in daily life activity to reduce falls in older adults. Aust Occup Ther J. 2010; 57(1):42-50. https://doi.org/10.1111/j.1440-1630.2009.00848.x.

107. Bauer J, Biolo G, Cederholm T, Cesari M, Cruz-Jentoft AJ, Morley JE, et al. Evidence-based recommendations for optimal dietary protein intake in older people: a position paper from the PROT-AGE study group. J Am Med Dir Assoc. 2013;14(8):542-59. https://doi.org/10.1016/j.jamda.2013.05.021.

108. Moore DR, Churchward-Venne TA, Witard O, Breen L, Burd NA, Tipton KD, et al. Protein ingestion to stimulate myofibrillar protein synthesis requires greater relative protein intakes in healthy older versus younger men. Gerontol A Biol Sci Med Sci. 2015;70(1):57-62. https://doi.org/10.1093/ gerona/glu103.

109. Mamerow MM, Mettler JA, English KL, Casperson SL, Arentson-Lantz E, Sheffield-Moore $M$, et al. Dietary protein distribution positively influences 24-h muscle protein synthesis in healthy adults. J Nutr. 2014;144(6):876-80. https://doi.org/10.3945/jn.113.185280.

110. Symons TB, Sheffield-Moore M, Wolfe RR, Paddon-Jones D. A moderate serving of high-quality protein maximally stimulates skeletal muscle protein synthesis in young and elderly subjects. J Am Diet Assoc. 2009:109(9):1582-6.

111. Cuthbertson D, Smith K, Babraj J, Leese G, Waddell T, Atherton P, et al. Anabolic signalling deficits underlie amino acid resistance of wasting, aging muscle. FASEB J. 2005;19(3):422-4. https://doi.org/10.1096/fj.04-2640fje.

112. Paddon-Jones $D$, van Loon L. Nutritional approaches to treating sarcopenia. In: Sarcopenia: Wiley; 2012. p. 275-95.

113. Health Promotion Board Singapore. Energy \& Nutrient Composition of food; 2011. Available at: https://focos.hpb.gov.sg/eservices/ENCF/. Accessed 23 Sep 2019

114. Berton L, Bano G, Carraro S, Veronese N, Pizzato S, Bolzetta F, et al. Effect of Oral Beta-Hydroxy-Beta-Methylbutyrate (HMB) supplementation on physical performance in healthy old women over 65 years: an open label randomized controlled trial. PLoS One. 2015;10(11):e0141757. https://doi. org/10.1371/journal.pone.0141757.

115. Stokes T, Hector AJ, Morton RW, McGlory C, Phillips SM. Recent Perspectives Regarding the Role of Dietary Protein for the Promotion of Muscle Hypertrophy with Resistance Exercise Training. Nutrients. 2018;10(2):180.

116. Cano NJ, Aparicio M, Brunori G, et al. ESPEN guidelines on parenteral nutrition: adult renal failure. Clin Nutr. 2009;28:401-14.

117. Ekinci O, Yanik S, Terzioglu Bebitoglu B, et al. Effect of calcium betahydroxy-beta-methylbutyrate (CaHMB), vitamin D, and protein supplementation on postoperative immobilization in malnourished older adult patients with hip fracture: a randomized controlled study. Nutr Clin Pract. 2016:31(6):829-35. https://doi.org/10.1177/0884533616629628.

118. Malafarina V, Uriz-Otano F, Malafarina C, et al. Effectiveness of nutritional supplementation on sarcopenia and recovery in hip fracture patients. A multi-Centre randomized trial. Maturitas. 2017;101:42-50.

119. Komar B, Schwingshackl L, Hoffmann G. Effects of leucine-rich protein supplements on anthropometric parameter and muscle strength in the elderly: a systematic review and meta-analysis. J Nutr Health Aging. 2015; 19(4):437-46. https://doi.org/10.1007/s12603-014-0559-4.

120. Deutz NE, Pereira SL, Hays NP, et al. Effect of beta-hydroxy-betamethylbutyrate (HMB) on lean body mass during 10 days of bed rest in older adults. Clin Nutr. 2013;32:704-12.

121. Hsieh LC, Chow CJ, Chang WC, Liu TH, Chang CK. Effect of beta-hydroxybeta-methylbutyrate on protein metabolism in bed-ridden elderly receiving tube feeding. Asia Pac J Clin Nutr. 2010;19(2):200-8.

122. Chew STH, Cheong M, Huynh DRR, et al. SUN-LB649: nutritional biomarkers in community-dwelling older people in Singapore. Clin Nutr. 2019:38:S3001. https://doi.org/10.1016/S0261-5614(19)32615-9. 
123. Beaudart C, Buckinx F, Rabenda V, Gillain S, Cavalier E, Slomian J, et al. The effects of vitamin D on skeletal muscle strength, muscle mass, and muscle power: a systematic review and meta-analysis of randomized controlled trials. J Clin Endocrinol Metab. 2014;99(11):4336-45. https://doi.org/10.1210/ jc.2014-1742.

124. Ross AC, Manson JE, Abrams SA, et al. The 2011 report on dietary reference intakes for calcium and vitamin D from the Institute of Medicine: what clinicians need to know. J Clin Endocrinol Metab. 2011;96:53-8.

125. Holick MF, Binkley NC, Bischoff-Ferrari HA, et al. Evaluation, treatment, and prevention of vitamin D deficiency: an Endocrine Society clinical practice guideline. J Clin Endocrinol Metab. 2011;96:1911-30.

126. Beaudart $C$, Rizzoli $R$, Bruyère $O$, Reginster JY, Biver E. Sarcopenia: burden and challenges for public health. Arch Public Health. 2014;72(1):45. https:// doi.org/10.1186/2049-3258-72-45.

127. Verlaan S, Maier AB, Bauer JM, Bautmans I, Brandt K, Donini LM, et al. Sufficient levels of 25-hydroxyvitamin $D$ and protein intake required to increase muscle mass in sarcopenic older adults - the PROVIDE study. Clin Nutr. 2018;37(2):551-7. https://doi.org/10.1016/j.clnu.2017.01.005.

128. Cermak NM, Res PT, de Groot LC, et al. Protein supplementation augments the adaptive response of skeletal muscle to resistance-type exercise training: a meta-analysis. Am J Clin Nutr. 2012;96(6):1454-64. https://doi.org/10.394 5/ajcn.112.037556.

129. Liao CD, Tsao JY, Wu YT, et al. Effects of protein supplementation combined with resistance exercise on body composition and physical function in older adults: a systematic review and meta-analysis. Am J Clin Nutr. 2017; 106:1078-91.

130. Antoniak AE, Greig CA. The effect of combined resistance exercise training and vitamin D3 supplementation on musculoskeletal health and function in older adults: a systematic review and meta-analysis. BMJ Open. 2017;7(7): e014619. https://doi.org/10.1136/bmjopen-2016-014619.

131. Yamada M, Kimura Y, Ishiyama D, Nishio N, Otobe Y, Tanaka T, et al. Synergistic effect of bodyweight resistance exercise and protein supplementation on skeletal muscle in sarcopenic or dynapenic older adults. Geriatr Gerontol Int. 2019;19(5):429-37. https:/doi.org/10.1111/ggi.13643.

132. Paddon-Jones D, Campbell WW, Jacques PF, Kritchevsky SB, Moore LL, Rodriguez NR, et al. Protein and healthy aging. Am J Clin Nutr. 2015;101(6): 1339S-45S. https://doi.org/10.3945/ajcn.114.084061.

133. Burd NA, Gorissen SH, van Loon L. Anabolic resistance of muscle protein synthesis with aging. Exerc Sport Sci Rev. 2013;41(3):169-73. https://doi. org/10.1097/JES.0b013e318292f3d5.

134. Kokura Y, Wakabayashi H, Maeda K, et al. Impact of a multidisciplinary rehabilitation nutrition team on evaluating sarcopenia, cachexia and practice of rehabilitation nutrition. J Med Investig. 2017;64:140-5.

135. Claflin DR, Larkin LM, Cederna PS, et al. Effects of high- and low-velocity resistance training on the contractile properties of skeletal muscle fibers from young and older humans. J Appl Physiol (1985). 2011;111:1021-30.

136. Giuffre S, Domholdt E, Keehan J. Beyond the individual: population health and physical therapy. Physiother Theory Pract. 2018;36(5):564-71. https://doi. org/10.1080/09593985.2018.1490364.

137. World Health Organization. Global action plan on physical activity 20182030: more active people for a healthier world. Geneva: World Health Organization; 2018. Available from: https://www.who.int/ncds/prevention/ physical-activity/global-action-plan-2018-2030/en/. Accessed 22 Feb 2021

\section{Publisher's Note}

Springer Nature remains neutral with regard to jurisdictional claims in published maps and institutional affiliations.

\section{Ready to submit your research? Choose BMC and benefit from:}

- fast, convenient online submission

- thorough peer review by experienced researchers in your field

- rapid publication on acceptance

- support for research data, including large and complex data types

- gold Open Access which fosters wider collaboration and increased citations

- maximum visibility for your research: over $100 \mathrm{M}$ website views per year

At $\mathrm{BMC}$, research is always in progress.

Learn more biomedcentral.com/submissions 